\title{
Human urine certified reference material CZ 6010: creatinine and toluene metabolites (hippuric acid and $o$-cresol) and a benzene metabolite (phenol)
}

\author{
I. Šperlingová • L. Dabrowská • V. Stránský • J. Kučera • \\ M. Tichý
}

Received: 5 June 2006 /Revised: 11 July 2006 / Accepted: 25 July 2006 / Published online: 5 September 2006

(C) Springer-Verlag 2006

\begin{abstract}
A reference material for the biological monitoring of occupational exposure to toluene, benzene and phenol was prepared. $O$-cresol and hippuric acid (metabolites of toluene) are used for the biological monitoring of occupational exposure to toluene. Phenol, a metabolite of benzene, is used for the biological monitoring of exposure to benzene, but phenol can of course also be used as an indicator of exposure to phenol as well. The reference material (RM) used for the determination of these metabolites was prepared by freeze-drying pooled urine samples obtained from healthy persons occupationally exposed to toluene and those taking part in an inhalation experiment. Tests for homogeneity and stability were performed by determining urine concentrations of $o$-cresol, hippuric acid, creatinine and phenol. To investigate the stability of the $\mathrm{RM}$, the urinary concentrations of $o$-cresol and phenol were monitored for eighteen months using GC and HPLC, while those of hippuric acid and creatinine were followed for five and six years, respectively, using HPLC. Analysis of variance showed that the concentrations did not change. The certified concentration values (and their uncertainties) of the substances in this reference material (phenol
\end{abstract}

\footnotetext{
I. Šperlingová $(\bowtie) \cdot$ L. Dabrowská $•$ V. Stránský $•$ M. Tichý Department of Toxicological Analysis,

National Institute of Public Health,

Šrobárova 48,

10042 Praha, Czech Republic

e-mail: sperling@szu.cz

J. Kučera

Academy of Science of Czech Republic,

Nuclear Physics Institute,

25068 Řež near Praha, Czech Republic

e-mail: kucera@ujf.cas.cz
}

concentration $c=6.46 \pm 0.58 \mathrm{mg} \mathrm{l}^{-1} ; o$-cresol concentration $c=1.17 \pm 0.15 \mathrm{mg} \mathrm{l}^{-1}$; hippuric acid concentration $c=1328 \pm$ $30 \mathrm{mg} 1^{-1}$; creatinine concentration $c=0.82 \pm 0.10 \mathrm{~g} \mathrm{l}^{-1}$ ) were evaluated via the interactive statistical programme IPECA.

Keywords Reference material - Toluene metabolites . $O$-cresol $\cdot$ Hippuric acid $\cdot$ Phenol $\cdot$ Creatinine

\section{Introduction}

In Europe there are thousands of industrial workers that are exposed to toluene. Toluene has narcotic and genotoxic effects $[1,2]$. A number of workplaces have been classified as being hazardous with respect to toluene [3].

Toluene is one of the most important industrial organic chemicals. It is absorbed by humans through the lungs, and $84 \%$ of the toluene absorbed is metabolized. Cytochrome P-450 enzymes are involved in several steps of the transformation of toluene. Toluene is metabolized into benzoic acid, which is further conjugated with glycine to form hippuric acid. Small amounts of absorbed toluene $(1 \%)$ are metabolized at the aromatic ring and excreted into the urine as $o-, m-$, and $p$-cresol [4-10].

Determinations of the concentrations of $o$-cresol and hippuric acid is used for biological monitoring of exposure to toluene. $O$-cresol is a more specific indicator of toluene exposure, because hippuric acid and $p$-cresol are natural components of urine [4-10].

In recent studies, another metabolite useful for the biological monitoring of toluene, $S$ - $p$-toluylmercapturic acid, which is not a natural component of urine, has been 
Table 1 Testing the concentration of $o$-cresol in RM 6010 for homogeneity

\begin{tabular}{|c|c|c|c|c|c|c|c|c|c|c|c|c|c|c|c|}
\hline \multirow[t]{2}{*}{ Metabolite sample } & \multicolumn{15}{|c|}{$O$-cresol ( $\mathrm{mg} \mathrm{l}^{-1}$ urine) } \\
\hline & 1 & 2 & 3 & 4 & 5 & 6 & 7 & 8 & 9 & 10 & 11 & 12 & 13 & 14 & 15 \\
\hline $\begin{array}{c}\text { Mean } \\
\text { value }\end{array}$ & 1.12 & 1.13 & 1.12 & 1.12 & 1.12 & 1.13 & 1.15 & 1.12 & 1.13 & 1.14 & 1.14 & 1.14 & 1.15 & 1.13 & 1.12 \\
\hline SD & 0.019 & 0.005 & 0.039 & 0.010 & 0.016 & 0.019 & 0.028 & 0.021 & 0.006 & 0.014 & 0.010 & 0.024 & 0.013 & 0.007 & 0.025 \\
\hline
\end{tabular}

described $[11,12]$. However, in practice no BAT (biological tolerance values) have been established for this substance yet [13].

Workers exposed to toluene have to undergo regular medical check-ups, which consist of a basic examination and the determination of urinary creatinine once each year. The concentrations of hippuric acid and $o$-cresol in urine are determined 1-3 times per year [14], so there is an urgent need for a certified reference material (RM) for those metabolites.

Biological limit values from biological exposure tests of urine and the conditions that should be used when sampling biological material during biological exposure tests are summarized in Decree No. 432/2003 Coll. [15].

In toxicology, the amount of toluene metabolite excreted in urine is expressed in either $\mathrm{mg} / \mathrm{l}$ of urine or in the concentrations per $\mathrm{mg}$ of excreted creatinine. Creatinine is excreted from the human body at a relatively stable rate which is only slightly influenced by physical exercise and stress and is not influenced by diet, temperature or volume of liquid imbibed. There are limitations to the monitoring of urinary creatinine excretion in the place of 24-h urine collection (the CVs reported by investigators have varied from 5.6 to $22 \%$ ) [16]. However, in occupational health praxes, the use of corrected urinary creatinine excretion is preferred to 24-h urine sampling. Thus, accurate creatinine determination becomes at least as important as the accurate determination of the analyte itself during the quality assurance of exposure analysis and exposure assessment.

The other analyte included in the RM developed here is phenol, which is a metabolite of benzene but can of course also be used as an indicator of exposure to phenol.

\section{Experimental}

The reference material was prepared by freeze-drying pooled urine samples [17] obtained from healthy persons occupationally exposed to toluene and those taking part in an inhalation experiment (9 males and 15 females, average age $47.2 \pm 14.9)$. Aliqots of urine $(12 \mathrm{ml})$ were dispensed into 20-ml glass vials using an automatic Nichiryo (Tokyo, Japan) Macromaster pipette, freeze-dried, and the vials were hermetically stoppered. Appropriate guidelines, such as Czech Metrological Institute Methodology 017 MPC001-02 [18], ISO Guide 352002 [19] and ISO Guide 34 2003 [20] were followed during RM preparation.

\section{Reconstitution of freeze-dried material}

The freeze-dried material was reconstituted for analysis by adding $12.00 \mathrm{ml}$ of bidistilled water and then by agitating this with a laboratory roller mixer at a frequency of $1 \mathrm{~s}^{-1}$ for $10 \mathrm{~min}$.

Instruments

HPLC was performed with an Agilent (Palo Alto, CA, USA) 1100 Series liquid chromatograph equipped with an autosampler and diode array detector as well as ChemStation software for analyte concentration evaluation.

GC was performed using:

- An Agilent 6890N gas chromatograph equipped with an autosampler and FID as well as ChemStation software for analyte concentration evaluation;

- An HP5890A gas chromatograph with FID and ECD;

- A Finnigan GCQ gas chromatograph with MS detector (ion trap).

Table 2 Testing the concentration of phenol in RM 6010 for homogeneity

\begin{tabular}{|c|c|c|c|c|c|c|c|c|c|c|c|c|c|c|c|}
\hline \multirow[t]{2}{*}{ Metabolite samples } & \multicolumn{15}{|c|}{ Phenol (mg $\mathrm{m}^{-1}$ urine) } \\
\hline & 1 & 2 & 3 & 4 & 5 & 6 & 7 & 8 & 9 & 10 & 11 & 12 & 13 & 14 & 15 \\
\hline Mean value & 6.22 & 6.10 & 6.15 & 6.19 & 6.20 & 6.23 & 6.32 & 6.16 & 6.27 & 6.24 & 6.23 & 6.53 & 6.38 & 6.25 & 6.29 \\
\hline SD & 0.04 & 0.04 & 0.05 & 0.04 & 0.10 & 0.15 & 0.31 & 0.11 & 0.04 & 0.12 & 0.04 & 0.31 & 0.13 & 0.08 & 0.12 \\
\hline
\end{tabular}


Table 3 Testing the concentration of hippuric acid in RM 6010 for homogeneity

\begin{tabular}{|c|c|c|c|c|c|c|c|c|c|c|}
\hline \multirow[t]{2}{*}{ Metabolite sample } & \multicolumn{10}{|c|}{ Hippuric acid (mg $1^{-1}$ urine) } \\
\hline & 1 & 2 & 3 & 4 & 5 & 6 & 7 & 8 & 9 & 10 \\
\hline Mean value & 1350.5 & 1350.5 & 1334.1 & 1348.3 & 1324.4 & 1334.4 & 1323.5 & 1322.8 & 1331.7 & 1325.0 \\
\hline SD & 14.7 & 12.8 & 14.0 & 41.5 & 20.3 & 14.6 & 18.4 & 15.4 & 10.2 & 12.2 \\
\hline
\end{tabular}

\section{Methods}

Creatinine concentrations were determined using an HPLC method [21] and spectrophotometrically (Jaffe's method) [22].

Two approaches to the HPLC determination of hippuric acid were used: separation on $\mathrm{C}-18$ columns and a Chromolith Performance RP/18e 100/4.6 with a Chromolith Guard Cartridge RP/18e 10/4.6 (Merck KgaA, Darmstadt, Germany) [23].

It was not necessary to purify the urine samples for both creatinine and hippuric determination; these were diluted with the mobile phase for the HPLC chromatography of hippuric acid and with bidistilled water for creatinine determination.

The phenol and $o$-cresol excreted in urine as glucuronides and sulfates were released via acidic hydrolysis performed by either simultaneous steam distillation or diisopropylether extraction, and so they were separated from most of the urine matrix. For phenol and $o$-cresol, four combinations of purification, separation and detection steps were employed [24]:

1. Gas chromatography with flame ionisation detection (GC/FID) (acidic hydrolysis followed by diisopropylether extraction);

2. Gas chromatography with flame ionisation detection (GC/FID) (acidic hydrolysis with simultaneous steam distillation followed by diisopropylether extraction);

3. Gas chromatography with electron capture detection (GC/ECD) (acidic hydrolysis with simultaneous steam distillation, derivatisation and heptane extraction);

4. Liquid chromatography with UV detection (HPLC) (acidic hydrolysis with simultaneous steam distillation - the same procedure as in procedures 2 and 3 above).
Calibration and traceability

Standard Reference Material NIST 914a creatinine was used as the calibration material for determinations of creatinine. Pure chemicals [phenol, no. 77610, lot 421187/1, $61703052,99.5 \%$ (w/w)(GC), o-cresol no. 60990, lot 14781/1, 14302004, 99.5\% (w/w)(GC) (Fluka, Buchs, Switzerland) and pure chemical hippuric acid ( $N$-benzoylaminoacetic acid), $>99 \%$ (Sigma-Aldrich, St. Louis, MO, USA), no. H-6375, lot 30K34723) were used for calibration when determining phenol and $o$-cresol concentrations. The declared purity was taken into account in the calibration function. This allowed the traceability of the results obtained to the pure substances mentioned above to be established.

Methods were validated by the method of standard addition, and results were evaluated using EffiValidation 3 software (EffiChem, Lysice, Czech Republic).

\section{Homogeneity tests}

Homogeneity testing was carried out by determining the phenol and $o$-cresol concentrations in fifteen units of RM (every 75th sample from the whole batch - not randomly chosen so as to avoid trend inhomogeneity). Three replicate analyses from each unit were performed using method GCFID-1 in the authors' laboratory.

Homogeneity testing for hippuric acid and creatinine concentration determinations was performed in ten units of RM (each 100th sample from the whole batch). Six replicate analyses from each unit were performed in the authors' laboratory using HPLC methods.

\section{Stability tests}

In order to make sure that the analyses were performed under conditions of good repeatability, the samples were

Table 4 Testing the concentration of creatinine in RM 6010 for homogeneity

\begin{tabular}{llllllllllll}
\hline Metabolite sample & \multicolumn{3}{l}{ Creatinine $\left(\mathrm{g} \mathrm{l}^{-1}\right.$ urine) } \\
\cline { 2 - 11 } & 1 & 2 & 3 & 4 & 5 & 6 & 7 & 8 & 9 \\
\hline Mean value & 0.75 & 0.72 & 0.72 & 0.72 & 0.71 & 0.69 & 0.72 & 0.70 & 0.71 & 0.73 \\
SD & 0.03 & 0.05 & 0.03 & 0.05 & 0.03 & 0.04 & 0.05 & 0.06 & 0.07 & 0.02 \\
\hline
\end{tabular}


Isochronic stability testing of o-cresol in preliminary batch of RM 6010

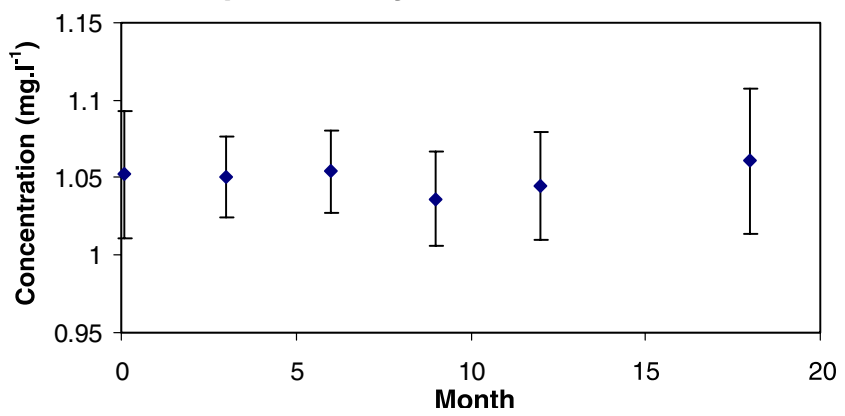

Fig. 1 Results from testing the stabilities of the $o$-cresol concentrations in samples stored in darkness at $3-6{ }^{\circ} \mathrm{C}$, (error bars are standard deviations of three replicate analyses)

analysed isochronically, i.e., all of the samples were analysed on the same day. To test the stabilities of phenol and $o$-cresol, two units of candidate RM were combined into one. The urinary concentrations were determined in six test portions of this RM after $0,3,6,9,18$ months after freeze-drying and storing the freeze dried material at $-18{ }^{\circ} \mathrm{C}$. Again, the method GC-FID-1 was used in the authors' laboratory. The stability of the creatinine concentration in RM 6008 was followed for six years, and the stability of the hippuric acid concentration in RM 6009 for five years.

\section{Design of interlaboratory comparison}

For the certification run, laboratories accredited by the Czech Accreditation Institute for this type of analysis or laboratories holding a Certificate for Toxicological Analyses in Biological Materials from the German External Quality Assessment Scheme Intercomparison Programme took part. Methods 1-4 were employed for phenol and $o$-cresol. Six individual units were pooled and then six subsamples taken from this pool were analysed over three consecutive days using each method. The laboratories were asked to carry out six replicate analyses of the RM each day. The aim of this repeated testing over a three-day period

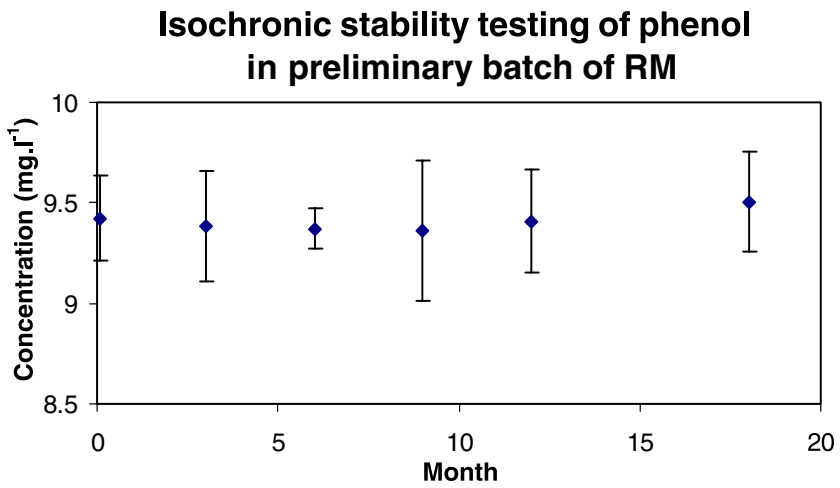

Fig. 2 Results from testing the stabilities of the phenol concentrations in samples stored in darkness at 3-6 ${ }^{\circ} \mathrm{C}$ (error bars are standard deviations of three replicate analyses)
Stability testing of hippuric acid concentration in RM 6009

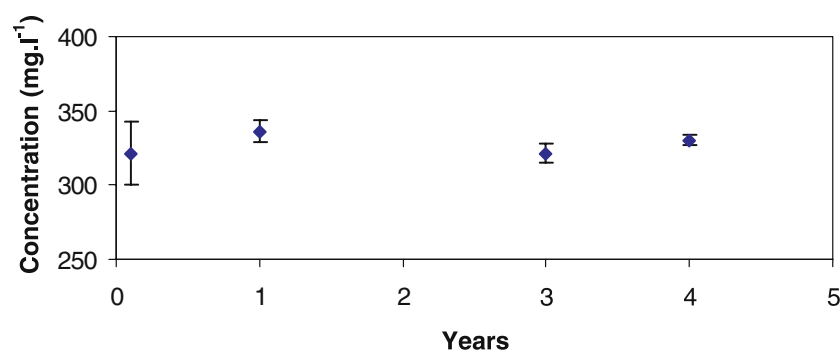

Fig. 3 Results from testing the stabilities of the hippuric acid concentrations in samples stored in darkness at 3-6 ${ }^{\circ} \mathrm{C}$ (error bars are standard deviations of six replicate analyses)

was to check the stabilities of the analytical methods employed. Hippuric acid and creatinine concentration determinations were carried out on one sample over three consecutive days. The analytical methods mentioned above were employed.

\section{Results and discussion}

Homogeneity tests

The results of homogeneity testing were examined using one-way analysis of variance (ANOVA). No significant between-unit differences were found for the concentrations of all of the analytes mentioned above considering the analytical uncertainty and the significance level used ( $\alpha=0.05$; Tables $1,2,3$ and 4). The overall mean \pm standard deviation values calculated for phenol, $o$-cresol, hippuric acid and creatinine were $6.25 \pm 0.09 \mathrm{mg}^{-1}$, $1.13 \pm 0.01 \mathrm{mg}^{-1}, 1334.5 \pm 17.4 \mathrm{mg}^{-1}$ and $0.72 \pm 0.04 \mathrm{~g} \mathrm{l}^{-1}$, respectively.

Stability tests

The results from testing the stabilities of the o-cresol, hippuric acid, phenol and creatinine concentrations in RM

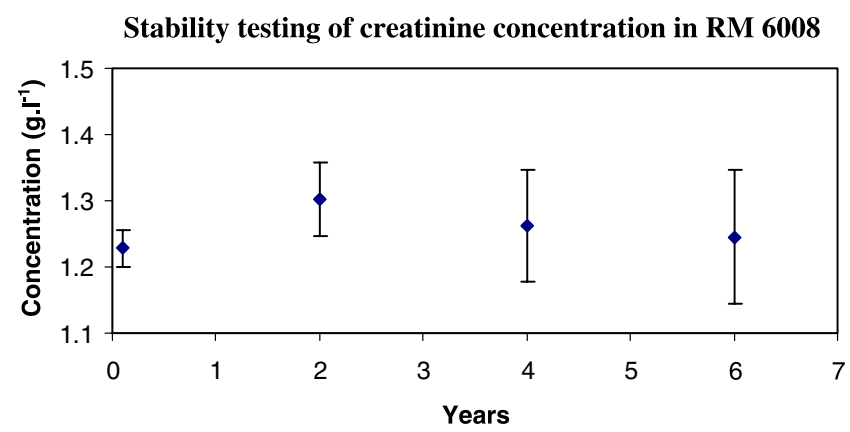

Fig. 4 Results from testing the stabilities of the creatinine concentrations in samples stored in darkness at $3-6{ }^{\circ} \mathrm{C}$ (error bars are standard deviations of six replicate analyses) 


\section{Interlaboratory comparison of o-cresol}

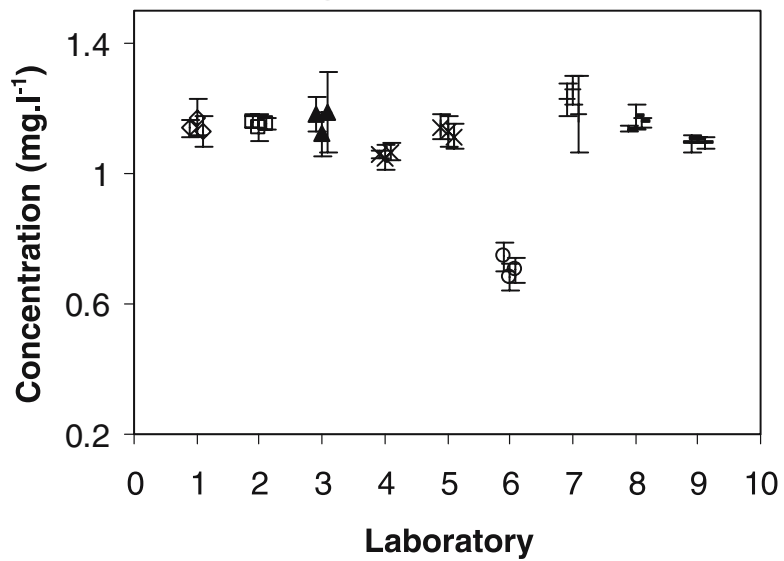

Fig. 5 Results from interlaboratory comparison for the determination of $o$-cresol in urine (error bars are standard deviations of six replicate analyses of each laboratory)

are summarized in (Figs. 1, 2, 3 and 4). Using one-way ANOVA, no concentration changes were found for any of these analytes over the period followed considering the analytical uncertainties and the significance level used $(\alpha=0.05)$. The overall mean \pm standard deviation calculated for phenol, $o$-cresol, hippuric acid and creatinine were $9.41 \pm 0.24 \mathrm{mg} \mathrm{l}^{-1}, 1.05 \pm 0.03 \mathrm{mg} \mathrm{l}^{-1}, 327.9 \pm 14 \mathrm{mg}^{-1}$ and $1.26 \pm 0.073 \mathrm{mg}^{-1}$, respectively.

\section{Evaluation of interlaboratory comparison}

The results from the interlaboratory comparison are summarized in Figs. 5, 6, 7 and 8.

The laboratory results obtained on three consecutive days were evaluated for agreement using one-way ANOVA. All of the laboratory tests passed this test. Then the individual laboratory means were evaluated using the IPECA interactive statistical programme [25]. The evaluation involves testing the variance of the laboratory data using the Cochran, Bartlett and standard error tests, and testing outlying laboratory means using the combined Grubb's, Dean-Dixon, Huber, coefficient of skewness and

\section{Interlaboratory comparison of phenol}

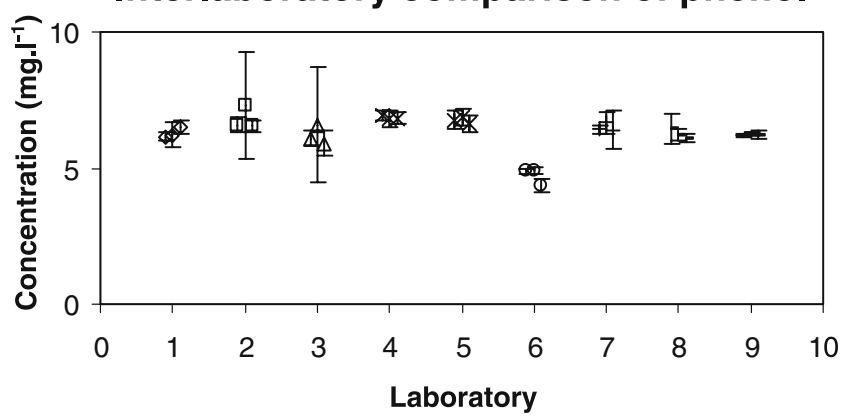

Fig. 6 Results from interlaboratory comparison for the determination of phenol in urine (error bars are standard deviations of six replicate analyses of each laboratory)
Interlaboratory comparison of hippuric acid concentrations in RM 6010

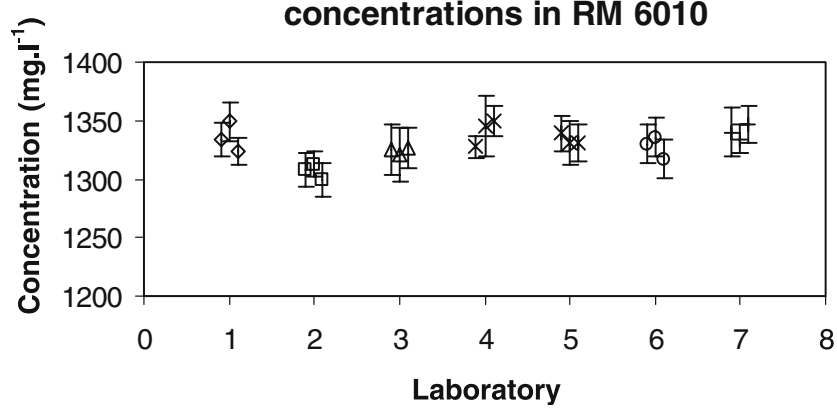

Fig. 7 Results from interlaboratory comparison for the determination of hippuric acid in urine (error bars are standard deviations of six replicate analyses of each laboratory)

kurtosis tests. The results from laboratory 6 for cresol were identified as being outliers for statistical reasons and were rejected from further data processing, because the laboratory was suspected of producing biased results for technical (calibration) reasons. Two outliers in the variance were found in the data sets obtained for phenol (laboratory 2 and 3). These data sets were therefore rejected from the calculation. To derive the certified values of the individual analytes, the overall arithmetic mean was calculated from the remaining laboratory means, and the combined uncertainty was calculated as $U=\sqrt{u_{i}^{2}+u_{h}^{2}+u_{s}^{2}}$ where $u_{i}^{2}$ is the uncertainty in the interlaboratory analyses (standard deviation of the overall mean), $u_{h}^{2}$ is the uncertainty in the homogeneity testing (standard deviation of the overall mean), and $u_{s}^{2}$ is the uncertainty in the stability testing (standard deviation of the overall mean).

The following certified values were obtained using the above approach:

- phenol: $(6.46 \pm 0.58) \mathrm{mg}^{-1}$

- o-cresol: $(1.17 \pm 0.15) \mathrm{mg} \mathrm{l}^{-1}$

- hippuric acid: $(1328 \pm 30) \mathrm{mg} \mathrm{l}^{-1}$

- creatinine: $(0.82 \pm 0.10) \mathrm{g} \mathrm{l}^{-1}$

The uncertainties given are combined uncertainties (coverage factor $=1$ ).

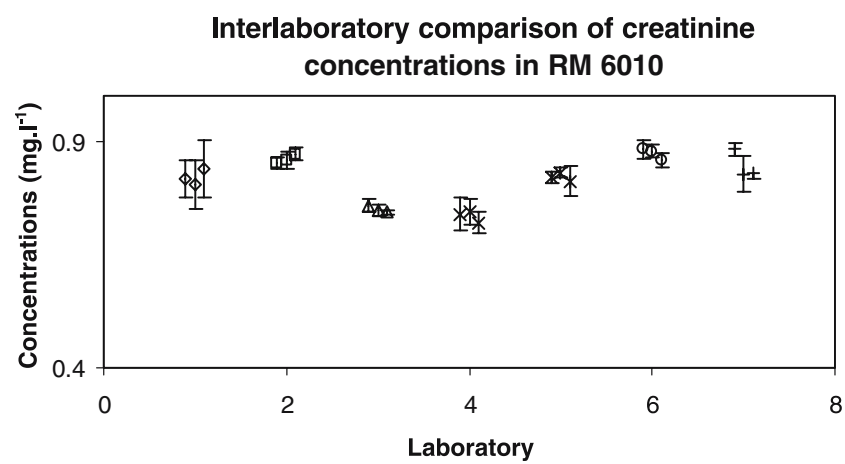

Fig. 8 Results from interlaboratory comparison for the determination of creatinine in urine (error bars are standard deviations of six replicate analyses of each laboratory) 


\section{Conclusion}

The reference material CZ 6010 for o-cresol and hippuric acid in human urine resulting from occupational toluene exposure has been prepared. Phenol and creatinine concentrations were also determined in the material. The certified values are unweighted arithmetical averages of accepted results from an interlaboratory comparison, and their uncertainties are combined uncertainties (coefficient $k=1$ ) evaluated from the standard uncertainties of the interlaboratory comparison, homogeneity and stability tests. The creatinine concentration was certified so that the contents of $o$-cresol, hippuric acid and phenol can be related to this parameter, as is often done in occupational health studies.

Acknowledgement This work was supported by the Internal Grant Agency of Ministry of Health of the Czech Republic (Grant NR/ 7831-3).

\section{References}

1. Pelclová D, Černá M, Pastorková A, Procházka B, Vrbíková V, Hurychová D, Dlasková Z, Hornychová M (2000) Arch Environ Health 55:268-273

2. Hammer KD (2002) Mutat Res 519:171-177

3. MZ (2006) Register of Czech National Health Information System, Register of Work Categorization $(\mathrm{KaPr})$, actualization 28.3.2006. Czech Ministry of Health (MZ), Prague (see http:// www.Healthcareregisters.cz, last accessed 15th August 2006)

4. Angerer J (1979) Int Arch Occup Environ Health 43:63-67

5. Pierce CH, Chen YL, Hurtle W, Morgan M (2004) J Toxicol Environ Health A 67:1131-1158
6. Angerer J (1985) Int Arch Occup Environ Health 56:323-328

7. Pierce CH, Chen Y, Dills R, Kalman DA, Morgan M (2002) Toxicol Lett 129:65-76

8. Truchon G, Tardif R, Brodeur J (1999) Appl Occup Environ Hyg 14:677-681

9. Fujii T, Kawabe S, Horike T, Taguchi T, Ogata Mx (1999) J Chromatogr B 730:41-47

10. Laurens JB, Mbianda XY, Spies JH, Ubbink JB, Vermaak WJH (2002) J Chromatogr B 774:173-185

11. Angerer J, Schildbach M, Kramer A (1998) Arch Toxicol $72: 119-123$

12. Inoue $\mathrm{O}$, Kanno $\mathrm{E}$, Yusa $\mathrm{T}$, Kakizaki M, Ukai H, Okamoto S, Higashikawa K, Ikeda M (2002) Int Arch Occup Environ Health 75:341-347

13. ACGIH (2002) Threshold limit values for chemical substances and physical agents and biological exposure indices. ACGIH, Cincinnati, OH, p 93

14. Society of Occupational Medicine (2006) Online documents. Society of Occupational Medicine of the Czech Medical Association of Jan Evangelista Purkyne, Prague (documents available from http://www.pracovni-lekarstvi.cz/dokumenty.php, last accessed 15th August 2006)

15. MZ (2003) Decree of the Ministry of Health No. 432/2003 Coll. Czech Ministry of Health (MZ), Prague

16. Stokes P, O’Connor GJ (2003) J Chromatogr B 794:125-136

17. Šperlingová I, Dabrowská L, Kučera J, Tichý M (1995) Fresenius J Anal Chem 352:87-91

18. ČMI (2002) Methodology 017 MP-C001-02. Czech Metrological Institute, Brno

19. ISO (2006) Guide 35. ISO/REMCO, Geneva

20. ISO (2003) Guide 34. ISO/REMCO, Geneva

21. Schneiderka P, Pacáková V, Štulík K, Jelínková K (1993) J Chromatogr 614:221

22. Jaffe M (1886) Z Physiol Chem 10:391

23. Šperlingová I, Dabrowská L, Stránský V, Tichý M (2004) Anal Bioanal Chem 378:536-543

24. Šperlingová I, Dabrowská L, Stránský V, Kučera J, Tichý M (2006) Accred Qual Assur 11:231-235

25. Kučera J, Faltejsek J (1995) Fresenius J Anal Chem 352:80-86 